\title{
Comparison of standard balloon and drug-coated balloon angioplasty in patients with the below- the-knee peripheral artery disease
}

\author{
Mehmet Ali Kaygin ${ }^{1 *} \odot$, Ümit Halici $\odot$
}

\section{SUMMARY}

OBJECTIVE: The objective of this study was to compare the interventions of percutaneous transluminal drug-coated balloon angioplasty (DCB PTA) and standard PTA in the treatment of patients with the below-the-knee peripheral artery disease (BTK PAD).

METHODS: Overall, 196 patients (113 males and 83 females; mean age: 63.56 \pm 11.94 years; 45-83 years) were treated with PTA for BTK PAD between June 2014 and March 2019.

RESULT: Standard PTA (group 1; 96 patients) and DCB PTA (group 2; 100 patients) results were analyzed and compared retrospectively. No statistically significant difference was found between the mean ages of group 1 and 2 patients $(p=0.371, p>0.05)$. Demographic and clinical data were compared and no any statistically significant differences was found between the two groups. Comparing in terms of the iliac lesion, there was no statistically significant difference between the two groups. However, a statistically significant difference was found between the two groups in terms of frequency of popliteal lesions ( $p=0.001 ; p<0.05)$. There was not a statistically significant difference between the two groups in terms of other lesions. In addition, limb salvage rates were $82.0 \%$ (18 amputations) and $65.6 \%$ (33 amputations) in the drug-release balloon group and the naked balloon group, at the end of 1 year, respectively. No distal embolism, limb-threatening ischemia, and mortality were observed in any patients.

CONCLUSIONS: Based on this study, patients in the DCB group had significantly higher rates of primary patency as compared with the other patients.

KEYWORDS: Peripheral artery disease. Drug coated balloon. Angioplasty. Stenting. Percutaneous. Transluminal.

\section{INTRODUCTION}

Peripheral artery disease (PAD) is usually characterized by intermittent claudication (IC), rest pain, ischemic ulcers, or gangrene. Over a 5-year period, 5-10\% of patients with asymptomatic PAD or IC will progress to critical limb ischemia $(\mathrm{CLI})^{1}$. Patients with CLI are at increased risk of amputation and major cardiovascular ischemic events ${ }^{2}$. Therefore, revascularization treatment of these patients must be planned as soon as possible.
Revascularization is an effective treatment modality despite the benefits of pharmacological agents. Selected revascularization treatment of the patient with CLI depends upon the premorbid conditions and the extremity as well as estimating the risk of intervention based on the comorbid conditions and expected patency and durability of the vascular reconstruction ${ }^{3}$. Although surgical revascularization is an effective revascularization method in the treatment of PAD, the existence of the patients with high surgical risk, lack of adequate venous conduit, and poor runoff in the infrapopliteal level and foot led to

\footnotetext{
'University of Health Sciences, Erzurum Regional Training and Research Hospital, Cardiovascular Surgery Department - Erzurum, Turkey. ¿2University of Health Sciences, Samsun Training and Research Hospital, Cardiovascular Surgery Department - Samsun, Turkey.

*Corresponding author: malikaygin@hotmail.com

Conflicts of interest: the authors declare there is no conflicts of interest. Funding: none.

Received on May 14, 2021. Accepted on July 13, 2021.
} 
a number of increasing percutaneous transluminal endovascular treatment (EVT) for revascularization. Nowadays, advancements in technique and technology have increased the feasibility and practicality of EVT, which now represents the preferred method of revascularization over surgical procedures in many centers across the world ${ }^{4}$. Unlike the open surgical technique, it can be performed under local anesthesia. Rapid application and rapid response, especially in emergency cases, enables EVT to be preferred method in patients with $\mathrm{CLI}^{5}$. On the other hand, the presence of long, calcific, and often occluded lesions in the infrapopliteal PAD negatively affects the patency rate after the EVT 5 . Since the optimal strategy for the management of a patient with CLI must be determined on a case-bycase basis ${ }^{6}$. Furthermore, patients should be informed about revascularization modalities and patients' preference should be questioned before the intervention.

It is known that drug-coated balloon (DCB) angioplasty and standard percutaneous transluminal angioplasty (PTA) (in other names are bare, naked, and old) are among EVT modalities. There is no consensus in the literature regarding the use of DCB or standard PTA in infrapopliteal lesions. This study aimed to compare the endovascular intervention techniques of DCB angioplasty and standard balloon angioplasty (PTA) in the treatment of patients with infrapopliteal PAD.

\section{METHODS}

Between June 2014 and March 2019, 196 patients (224 limb intervention) (113 males and 83 females; mean age: $63.56 \pm 11.94$ years; $45-83$ years) with infrapopliteal PAD who underwent endovascular revascularization operation were enrolled in this retrospective single-center study. Standard balloon angioplasty and DCB angioplasty were performed in 96 (group 1 patients' mean ages: 64.27 \pm 10.45 ) and 100 (group 2 patients' mean ages: $62.83 \pm 11.94)$ patients, respectively. Color flow Doppler ultrasound and peripheral digital subtraction or computed tomography angiography were performed after the physical examination in all patients. Control radiological imaging studies were performed during the intervention or after the procedure if needed.

Inclusion criteria were determined as lifestyle-limiting IC or CLI (Rutherford classification stages 3-6). During EVT procedure, ipsilateral or contralateral femoral artery was used for the arterial access. In case of flow-restricting dissection or $\geq 30 \%$ residual stenosis, the inflation time was prolonged (3 min) during the intervention. Exclusion criteria were life expectancy of less than 1 year, contraindication for dual-antiplatelet therapy, known allergy against paclitaxel, and a requirement for extensive amputation during the procedure.
Also, patients with infrapopliteal vascular disease were excluded from the study if they were diagnosed with Buerger's disease. Patients received medical treatment postoperatively. Patients were called up at 1,3 , and 6 months after the procedure and followed up with ankle-brachial index (ABI) measurements and Rutherford classification. In the demographic data of patients, 6-month patency and clinical status were compared between the groups.

The primary termination variables were freedom from amputation, restenosis, and reintervention. Secondary termination variables were technical success, procedural and postoperative complications, conventional primary patency, secondary restenosis, tissue healing, limb salvage, reintervention, and patient survival. Technical success was defined as an angiographic evaluation $<30 \%$ residual stenosis after the procedure and direct flow to the target site. Treatment failure was defined as any patient requiring reintervention, with/or without restenosis and/or occlusion and reintervention was performed. Also, these patients had decreasing ABI.

Following the procedure, $300 \mathrm{mg}(75 \mathrm{mg} \times 4)$ clopidogrel loading was given, followed by dual-antiplatelet therapy $(75 \mathrm{mg}$ clopidogrel and $100 \mathrm{mg}$ acetylsalicylic acid daily) and cilostazol (200 mg daily) for 12 months. Also, intravenous iloprost (20 $\mu \mathrm{g}$ daily) was routinely given to all patients early postintervention term for 10 days. At the end of 6 months, clopidogrel was stopped, and patients were followed with $100 \mathrm{mg}$ acetylsalicylic acid daily.

\section{Statistical analysis}

Statistical analysis was performed using SPSS mac v.20 statistical package program (IBM, Armonk, NY, USA). The suitability of the data for normal distribution was examined by the Kolmogorov-Smirnov test. Variables showing normal distribution were compared with parametric tests (Student's t-test), and mean \pm standard deviation values were used as descriptive statistics. The variables not normally distributed were compared with nonparametric tests (Mann-Whitney U), and median (lower quarter-upper quarter) values were given as descriptive statistics. Pearson's chi-square and Fisher's exact tests were used for the analysis of categorical data. The $\mathrm{p}<0.05$ were considered statistically significant. Major amputation was defined as loss of limb above the metatarsal level, whereas small amputation was defined as trans-metatarsal amputation or amputation of the more distal parts of the lower limb.

\section{RESULTS}

There was not any statistically significant difference between the mean age of group 1 and 2 patients $(\mathrm{p}=0.371, \mathrm{p}>0.05)$. 
Demographic and clinical data were compared and found no statistically significant difference between the two groups (Table 1). Lower limb-threatening ischemia and distal embolism were not seen in any patient who enrolled in this study.

Based on the iliac lesion, there was no statistically significant difference between the two groups but iliac stent application was performed in two patients (2.1\%) of group $2(\mathrm{p}=0.239)$. In all, 52 patients in group 2 and 27 patients in group 1 had popliteal lesions and there was a statistically significant difference between the two groups in terms of frequency of popliteal lesions $(\mathrm{p}=0.001 ; \mathrm{p}<0.05)$. There was no statistically significant difference between the two groups in terms of other lesions. Lesion features are provided in detail in Table 2. Rutherford classification and ABI were used in the follow-up of the clinical recovery after the procedure. There was no significant difference between the two groups at the beginning; however, clinical improvement was significantly higher in the DCB balloon group with medication at the end of 6 months. Besides, limb salvage rates were $82.0 \%$ (18 amputations) and $65.6 \%$ (33 amputations) in the DCB balloon group and the naked balloon group, at the end of 6 months, respectively. There was statistically significant difference between the two groups $(\mathrm{p}=0.009)$.

\section{DISCUSSION}

The first percutaneous EVT for PAD was described by Dotter and Judkins in the mid-1960s ${ }^{7}$. It was reported that for selected patient population with ischemic diabetic foot and isolated infrapopliteal lesions, a successful EVT led to a high percentage of limb salvage at the long-term follow-up ${ }^{8}$. However, the application of standard PTA is limited due to complications associated with the endovascular procedure

Table 1. Patient demographics.

\begin{tabular}{l|c|c|c}
\hline Number/percentage, $\mathrm{n}(\%)$ & Group 1 $(\mathrm{n=96)}$ & Group 2 $(\mathrm{n}=100)$ & p-value \\
\hline Gender (male/female) & $55 / 41(57.3 / 42.7)$ & $58 / 42(58.0 / 42.0)$ & 0.920 \\
\hline Smoker & $60(62.5)$ & $70(70.0)$ & 0.267 \\
\hline Diabetes mellitus & $52(54.2)$ & $54(54.0)$ & 0.981 \\
\hline Hypertension $(\geq 130 / 80 \mathrm{mmHg})$ & $45(46.9)$ & $55(55.0)$ & 0.255 \\
\hline Dyslipidemia $(\mathrm{LDL} \geq 200 \mathrm{mg} / \mathrm{dL})$ & $58(60.4)$ & $54(54.0)$ & 0.364 \\
\hline Coronary artery disease & $60(62.5)$ & $52(52.0)$ & 0.138 \\
\hline $\begin{array}{l}\text { Chronic renal failure } \\
\text { Creatinine }>2.0 \mathrm{mg} / \mathrm{dL}\end{array}$ & $3(3.1)$ & $5(5.0)$ & 0.721 \\
\hline Cerebrovascular disease & $11(11.5)$ & $13(13.0)$ & 0.742 \\
\hline
\end{tabular}

LDL: low-density lipoprotein.

Table 2. Lesion angiographic and procedural features.

\begin{tabular}{l|c|c|c} 
& Group 2 & Group 1 & p-values \\
\hline Lesion length, cm & $12.3 \pm 7.60$ & $13.7 \pm 8.76$ & 0.0019 \\
\hline Angiography lesion length, cm & $7.89 \pm 4.17$ & $7.97 \pm 7.46$ & 0.060 \\
\hline Restenotic lesions & $6.7(24 / 359)$ & $3.7(7 / 189)$ & 0.176 \\
\hline \% Diameter stenosis (before procedure) & $91.2 \pm 9.8$ & $90.71 \pm 9.29$ & 0.065 \\
\hline \% Diameter stenosis (after procedure) & $19.8 \pm 10.1$ & $20.2 \pm 11.7$ & 0.068 \\
\hline Maximum inflation pressure, atm & $6.9 \pm 3.4$ & $11.2 \pm 4.8$ & 0.015 \\
\hline Procedure complications* & $9.7(23 / 238)$ & $3.4(4 / 119)$ & 0.035 \\
\hline Distal embolization & $2.8(9 / 319)$ & $0.6(1 / 169)$ & 0.176 \\
\hline
\end{tabular}

*Vessel rupture, vessel dissections, peripheral emboli, and hematoma. 
and a relatively high restenosis rate. PTA treatment may result in residual stenosis, early elastic recoil, and flow-limiting dissection?.

Lack of desired results caused by high restenosis with the bare metal stent and standard balloon applications in infrainguinal lesions led to the technological innovation of locally administered DCB and drug-coated stents ${ }^{10}$. Drug-coated stents were developed in 1999 to provide local administration of an agent without systemic side effects, which have capable of inhibiting intimal hyperplasia caused by an inflammatory reaction following stent implantation or balloon expansion ${ }^{11}$. In this way, the cellular mechanisms responsible for atherosclerosis and neointimal hyperplasia are inhibited.

Ipema et al. reported in their meta-analysis that no significant differences were found between DCB angioplasty and standard PTA angioplasty in patients with infrapopliteal $\mathrm{PAD}^{12}$. On the other hand, Schmidt et al. reported that the early restenosis rate of long-segment infrapopliteal disease is significantly lower after treatment with DCBs compared with historical data using uncoated balloons ${ }^{13}$. Also, Roh et al..$^{14}$ reported that treatment of the complex femoropopliteal arterial occlusive disease with DCBs showed excellent primary patency and target lesion revascularization-free survival at 1 year after the procedure. In this study, similar results were obtained in parallel with the literature.

When the disease affects infrapopliteal level, frequency of lesion increases in other parts of the limb. In this study, the incidence of superficial femoral artery lesion was 45.8 and $47 \%$ in patients with bare balloon PTA and DCB, respectively. In both groups, when the lesions complicated, this has a negative effect especially on the success of the long-term results of angioplasty.

Fernandez et al. ${ }^{15}$ reported that tibial artery endovascular intervention is an effective treatment for CLI with acceptable limb salvage and wound healing rates, but endovascular intervention requires a high rate of reintervention. Gür et al. ${ }^{5}$ reported that DCBs are found superior to naked balloons at 12-month patency rates and clinical follow-up. The authors also pointed out that DCB application gives successful results in the long term and have positive contributions to limb salvage in cases with BTK lesions ${ }^{5}$. In this study, the clinical results of the DCB group were superior to the bare balloon group in the 6-month follow-up. Also, Liistro et al. ${ }^{16}$ reported in their study on drug-eluting balloon in peripheral intervention for belowthe-knee angioplasty evaluation trial that DCBs compared with PTA strikingly reduce 1-year restenosis, target lesion revascularization, and target vessel occlusion in the treatment of BTK lesions in the diabetic patients with CLI. Similarly, lower lumen loss was detected at 6 months in the DCB group compared with standard balloon angioplasty group $(0.4 \pm 1.2 \mathrm{~mm}$ versus $1.7 \pm 1.8 \mathrm{~mm} ; \mathrm{p}<0.001)$ in THUNDER trial ${ }^{17}$.

We can conclude that increased clinical healing, walking distance, and wound healing and low amputation rates are seen after the DCB angioplasty. Accordingly, ABI rates and Rutherford levels of the patients are also improved compared with pretreatment. In this study, the improvement of the patients' status was better in current situations in the DCB group.

Interestingly, Katsanos et al. ${ }^{18}$ reported that there seems to be an increased long-term risk of death beyond the first year after the intervention of femoropopliteal application of paclitaxel-coated balloons and stents in the lower limbs. They also mentioned that actual causes for this serious late side effect remain unknown, and further investigations with longer term follow-up are urgently warranted. On the other hand, Zeller et al. ${ }^{19}$ reported that paclitaxel exposure was not related to increased risk for amputation or all-cause mortality at 5-year follow-up. Similarly, any patient did not develop such a complication in this study (increased death associated with paclitaxel).

There is another limitation in the literature. A long ( $>3 \mathrm{~min})$ inflation period during balloon dilatation may prove effective as an initial angioplasty strategy to prevent severe dissection in femoropopliteal lesions ${ }^{20}$. Although longer inflation time did not improve primary patency within 1 year, it might result in better immediate angioplasty success ${ }^{20}$. Moreover, Rockley et al. ${ }^{21}$ reported that both coronary and peripheral vascular evidence are in agreement that prolonged angioplasty balloon inflation greater than 60 seconds appears to be associated with improved immediate postinflation results. This shows that prolonged inflation time improves patency rates in $\mathrm{DCB}$ compared with PTA. Similarly, the inflation time was 3 min in this study.

\section{CONCLUSIONS}

In conclusion, DCB group had significantly higher rates of primary patency as compared with the PTA group, although there was no statistically significant difference between the two groups in terms of limb recovery, survival, and restenosis rates between DCB angioplasty and standard PTA. We think that it should be supported by high population, differently designed devices, and studies.

\section{AUTHORS' CONTRIBUTIONS}

MAK: Conceptualization, Data curation, Formal analysis, Project administration, Writing - original draft, Writing review \& editing. ÜH: Formal analysis, Software, Supervision, Writing - review \& editing. 


\section{REFERENCES}

1. Díaz-Sandoval LJ. Diagnostic and therapeutic approaches in the management of infrapopliteal arterial disease. Interv Cardiol Clin. 2020;9(2):207-20. https://doi.org/10.1016/j. iccl.2019.12.006

2. Gerhard-Herman MD, Gornik HL, Barret C, Barshes NR, Corriere MA, Drachman DE, et al. 2016 AHA ACC guideline on the management of patients with lower extremity peripheral artery disease: a report of the American College of Cardiology/ American Heart Association Task Force on Clinical Practice Guidelines. Circulation. 2017;135(12):e726-e779. https:// doi.org/10.1161/CIR.0000000000000471. Erratum in: Circulation. 2017;135(12):e791-e792. https://doi.org/10.1161/ CIR.0000000000000502

3. Norgren L, Hiatt WR, Dormandy JA, Nehler MR, Harris KA, Fowkes FG, et al. Inter-society consensus for the management of peripheral arterial disease (TASC II). J Vasc Surg. 2007;45 Suppl:S5-67. https://doi.org/10.1016/j.jvs.2006.12.037

4. Bunte MC, Shishehbor MH. Next generation endovascular therapies in peripheral artery disease. Prog Cardiovasc Dis. 2018;60(6):593-9. https://doi.org/10.1016/j.pcad.2018.03.003

5. Gür O, Donbaloğlu MO, Gürkan S. Diz Altı Periferik arter hastalığı bulunan olgularda ilaç salınımlı balon ile çıplak balon sonuçlarının karşılaştırılması. Duzce Medical Journal. 2018;20(3):73-6. https://doi.org/10.18678/dtfd.471875

6. Hirsch AT, Haskal ZJ, Hertzer NR, Bakal CW, Creager MA, Halperin JL, et al. ACC/AHA Guidelines for the management of patients with peripheral arterial disease (lower extremity, renal, mesenteric, and abdominal aortic): a collaborative report from the American Associations for Vascular Surgery/Society for Vascular Surgery, Society for Cardiovascular Angiography and Interventions, Society for Vascular Medicine and Biology, Society of Interventional Radiology, and the ACC/AHA Task Force on Practice Guidelines (writing committee to develop guidelines for the management of patients with peripheral arterial disease) --summary of recommendations. J Vasc Interv Radiol. 2006;17(9):1383-97. quiz 1398. https://doi. org/10.1097/01.RVI.0000240426.53079.46

7. Balzer JO, Khan V, Thalhammer A, Vogl TJ, Lehnert T. Below the knee PTA in critical limb ischemia results after 12 months: single center experience. Eur J Radiol. 2010;75(1):37-42. https://doi.org/10.1016/j.ejrad.2010.04.014

8. Ferraresi R, Centola M, Ferlini M, Da Ros R, Caravaggi C, Assaloni $R$, et al. Long-term outcomes after angioplasty of isolated, below-the-knee arteries in diabetic patients with critical limb ischemia. Eur J Vasc Endovasc Surg. 2009;37(3):336-42. https://doi.org/10.1016/j.ejvs.2008.12.001

9. Kasapis C, Gurm HS. Current approach to the diagnosis and treatment of femoral-popliteal arterial disease. A systematic review. Curr Cardiol Rev. 2009;5(4):296-311. https://doi. org/10.2174/157340309789317823

10. Sarode K, Spelber DA, Bhatt DL, Mohammad A, Prasad A, Brilakis ES, et al. Drug delivering technology for endovascular management of infrainguinal peripheral artery disease. JACC Cardiovasc Interv. 2014;7(8):827-39. https://doi.org/10.1016/j. jcin.2014.05.008
11. Maeda K, Ohki T. Endovascular therapeutic technique. In: Sidawy AN, Perler BA, eds. Rutherford's Vascular Surgery and Endovascular Therapy. $9^{\text {th }}$ ed. Philadelphia: Elsevier; 2019. p 762-84.

12. Ipema J, Huizing E, Schreve MA, de Vries JPPM, Ünlü Ç. Editor's Choice - Drug coated balloon angioplasty vs. standard percutaneous transluminal angioplasty in below the knee peripheral arterial disease: a systematic review and metaanalysis. Eu J Vasc Endovasc Surg. 2020;59(2):265-75. https:// doi.org/10.1016/j.ejvs.2019.10.002

13. Schmidt A, Piorkowski $M$, Werner $M$, Ulrich $M$, Bausback $Y$, Bräunlich $S$, et al. First experience with drug-eluting balloons in infrapopliteal arteries: restenosis rate and clinical outcome. J Am Coll Cardiol. 2011;58(11):1105-9. https://doi.org/10.1016/j. jacc.2011.05.034

14. Roh JW, Ko YG, Ahn CM, Hong SJ, Shin DH, Kim JS, et al. Risk factors for restenosis after drug-coated balloon angioplasty for complex femoropopliteal arterial occlusive disease. Ann Vasc Surg. 2019;55:45-54. https://doi.org/10.1016/j. avsg.2018.06.015

15. Fernandez N, McEnaney R, Marone LK, Rhee RY, Leers S, Makaroun $M$, et al. Predictors of failure and success of tibial interventions for critical limb ischemia. J Vasc Surg. 2010;52(4):834-42. https://doi.org/10.1016/j.jvs.2010.04.070

16. Liistro F, Porto I, Angioli P, Grotti S, Ricci L, Ducci K, et al. Drug-eluting balloon in peripheral intervention for below the knee angioplasty evaluation (DEBATE-BTK): a randomized trial in diabetic patients with critical limb ischemia. Circulation. 2013;128(6):615-21. https://doi.org/10.1161/ CIRCULATIONAHA.113.001811

17. Chow CL, Scott P, Farouque O, Clark DJ. Drug-coated balloons: a novel advance in the percutaneous treatment of coronary and peripheral artery disease. Interv Cardiol. 2015;7(2):169-80. Available from: https://www.openaccessjournals.com/articles/ drugcoated-balloons-a-novel-advance-in-the-percutaneoustreatment-of-coronary-and-peripheral-artery-disease.pdf

18. Katsanos K, Spiliopoulos S, Kitrou P, Krokidis M, Karnabatidis D. Risk of death following application of paclitaxel-coated balloons and stents in the femoropopliteal artery of the leg: a systematic review and meta-analysis of randomized controlled trials. J Am Heart Assoc. 2018;7(24):e011245. https://doi. org/10.1161/JAHA.118.011245

19. Zeller T, Micari A, Scheinert D, Baumgartner I, Bosiers M, Vermassen FEG, et al. The IN.PACT DEEP clinical drug-coated balloon trial: 5-year outcomes. JACC Cardiovasc Interv. 2020;13(4):431-43. https://doi.org/10.1016/j.jcin.2019.10.059

20. Horie K, Tanaka A, Taguri M, Kato S, Inoue N. Impact of prolonged inflation times during plain balloon angioplasty on angiographic dissection in femoropopliteal lesions. J Endovasc Ther. 2018;25(6):683-91. https://doi. org/10.1177/1526602818799733

21. Rockley M, Jetty P, Radonjic A, Rockley K, Wells G, Fergusson $D$. Prolonged versus brief balloon inflation during arterial angioplasty for de novo atherosclerotic disease: a systematic review and meta-analysis. CVIR Endovasc. 2019;2(1):29. https://doi.org/10.1186/s42155-019-0072-2 